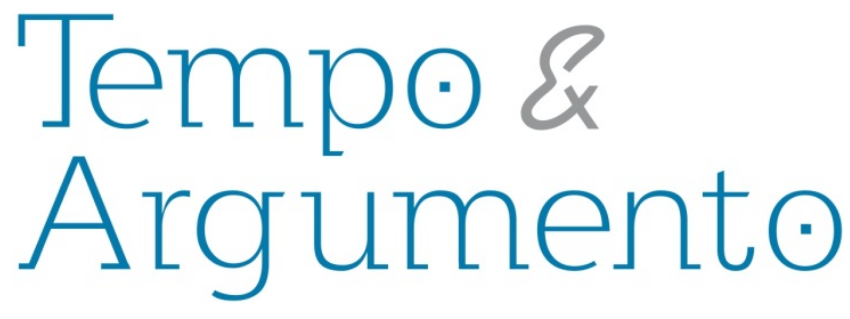

\title{
Os movimentos docentes brasileiro e português na virada dos anos $1970-80^{1}$
}

\begin{abstract}
Resumo
O artigo analisa as ações e manifestações docentes ocorridas no Brasil e em Portugal, nos anos 1970-80, período marcado pelo declínio dos regimes autoritários e pela ascensão de movimentos de contestação política aos poderes constituídos. A primeira seção propõe uma reflexão teórica a respeito das potencialidades analíticas de conceitos como estrutura de oportunidades políticas para compreender os movimentos sociais; a segunda sessão apresenta algumas particularidades da participação dos professores nos processos de transição política em curso nos dois países. Nas terceira e quarta seções, são analisados os repertórios de ação dos movimentos docentes brasileiro e português. A última seção conclui com uma síntese das concepções partilhadas pelos professores nas lutas por mudanças políticas e pela construção da escola democrática.
\end{abstract}

Palavras-chave: Transição democrática. Movimentos docentes. História da educação.

\author{
Libania Nacif Xavier \\ Doutora em Educação Brasileira pela \\ Pontifícia Universidade Católica do \\ Rio de Janeiro. Pós-doutorado na \\ Universidade de Lisboa. Professora \\ Associada da Faculdade de \\ Educação da Universidade Federal \\ do Rio de Janeiro. \\ libaniaxavier@hotmail.com
}

\section{Para citar este artigo:}

XAVIER, Libania Nacif. Os movimentos docentes brasileiro e português na virada dos anos 1970 80. Revista Tempo e Argumento, Florianópolis, v. 5, n.10, jul./dez. 2013. p. 234 - 257.

\section{DOI: $10.5965 / 2175180305102013234$}

http://dx.doi.org/10.5965/2175180305102013234

\footnotetext{
${ }^{1}$ A pesquisa contou com bolsa pós-doutoral da Capes, com recursos do Edital Universal CNPq e com bolsas de iniciação científica do CNPq e FAPERJ.
} 


\title{
The brazilian and protuguese faculty movements at the turn of the decade 1970 s to 1980 s
}

\begin{abstract}
The goal of this article is to analyze faculty actions and manifestations in Brazil and Portugal, in the 1970s-1980's, a period characterized by the decline of authoritarian governments and the ascension of political movements which challenged established authorities. In the first section we propose a theoretical reflection about the concept of political opportunities structures to understand social mobilizations. The second section presents some particularities of the faculty's participation in the process of political changes in both countries.. The third and fourth sections focus on the Brazilian and Portuguese faculty movements action repertories. . The last section presents the main ideas shared by them in order to get political changes and make the school more democratic
\end{abstract}

Keywords: Democratic transition. Faculty movements. History of education.

O artigo aborda as ações e manifestações docentes ocorridas no Brasil e em Portugal, em um período marcado pelo declínio dos regimes autoritários vigentes em países da América Latina e da Europa e, também, pela ascensão de movimentos de contestação política e de ampliação da participação popular nas grandes questões de caráter nacional e internacional. Nesse empenho, destaca as características dos movimentos docentes, identificando os seus repertórios de ação coletiva, assim como as respostas políticas que o grupo dirigiu aos poderes governamentais em meio ao processo de transição democrática que pontuou os contextos políticos brasileiro e português, na virada dos anos 1970-80. 
No âmbito da participação docente, verifica-se a mobilização em prol da reativação das organizações sindicais, tendo em vista a reestruturação da carreira e a luta pelo direito à livre associação. Apesar de terem se desenvolvido numa ambiência de recrudescimento das lutas democráticas e de expectativas de transformação política e social tanto em um como em outro lado do Atlântico, não se pode negligenciar as particularidades que marcaram a história de cada país, o que determinou que os movimentos docentes fossem abordados em separado, destacando-se, no caso português, a criação dos Grupos de Estudos do Pessoal Docente do Ensino Secundário e, no caso brasileiro, as greves dos professores públicos do Rio de Janeiro, ocorridas em 1979 e 1988.

Assim, a primeira seção propõe uma reflexão a respeito das potencialidades analíticas do conceito de estrutura de oportunidades políticas para a compreensão dos movimentos docentes. A segunda sessão apresenta algumas especificidades da participação dos professores nos processos de transição política que marcaram os contextos brasileiro e português das décadas de 1970-80. Nas terceira e quarta seções, são analisados os repertórios de ação mobilizados pelos professores no Brasil e em Portugal. A última seção apresenta uma síntese das concepções e expectativas partilhadas pelos professores nos movimentos analisados.

\section{Movimentos Docentes e oportunidade política}

No livro intitulado Teorias dos Movimentos Sociais: paradigmas clássicos e contemporâneos, Maria da Glória Gohn (2008) apresenta uma alentada síntese sobre as tradições de pesquisa que têm orientado o estudo dos movimentos coletivos. A autora identifica os grandes eixos de abordagem do tema, tais como: o paradigma norteamericano e as teorias da mobilização de recursos; os estudos europeus com o paradigma marxista e o paradigma dos Novos Movimentos Sociais; os estudos latinoamericanos e as abordagens das estruturas das oportunidades políticas.

Entre os estudos europeus, a autora destaca a abordagem marxista e a dos Novos Movimentos Sociais. A abordagem marxista centra-se no estudo dos processos históricos 
política dos novos atores sociais. Por seu turno, o paradigma norte-americano possui, em suas diferentes versões, explicações centradas mais na estrutura das organizações dos chamados sistemas sociopolítico e econômico, explicando os movimentos sociais, não em âmbito individual, mas organizacional. A variável mais importante desse tipo de análise é a dos recursos humanos, financeiros e de infraestrutura, aos quais se atribui influência decisiva para a emergência dos movimentos sociais. Nessa linha se chega à conclusão de que os movimentos surgem quando se estruturam oportunidades políticas para ações coletivas, assim como quando facilidades e líderes estão em disponibilidade. Os movimentos também estruturam o seu cotidiano segundo o estoque de recursos que possuem, sendo os principais os econômicos, humanos e de comunicação (GOHN, 2008, p. 53-56).

Do debate entre os teóricos europeus e os norte-americanos, Gohn (2009:17) identifica, ainda, uma nova forma de abordagem que predominou na América Latina, e na qual a grande ênfase se encontra do processo político das mobilizações e nas bases culturais que lhes dão sustentação. Assim, a corrente dos chamados Novos Movimentos Sociais destaca o processo de construção da identidade política dos movimentos e seu potencial de resistência (cultural). Na América do Norte, as teorias que resultaram das discussões dos anos 1980 também enfatizaram o processo político, em especial o jogo de poder entre a sociedade civil e as estruturas governamentais, resultando deste jogo as estruturas das oportunidades políticas (EOP).

Conforme observaram McAdam; Tarrow e Tilly (2009 p. 27) os movimentos sociais se desenvolvem dentro de limites colocados por estruturas prevalecentes de oportunidade política. Isto quer dizer que a repressão e a facilitação das reivindicações pelas autoridades públicas, a presença de aliados potenciais, rivais ou inimigos, afetam, de forma significativa, qualquer padrão de confronto do sistema político. Contudo, é importante destacar com os autores que, num prazo mais longo, a ação do movimento social também altera as estruturas de oportunidade, principalmente ao contribuir para 
a capacidade de mobilização social, gerando incentivos à formação de organizações civis. MacAdam (1997), em particular, identifica alguns aspectos que podem influenciar o repertório de ações coletivas no âmbito da sociedade civil, tais como a abertura política do sistema, as mudanças no apoio a movimentos sociais por parte das elites e a propensão estatal para a repressão. Nesse sentido, as alterações no equilíbrio das relações de poder entre as elites, o Estado e a sociedade civil ganham relevância para o nosso estudo.

Em que pesem as críticas dirigidas ao conceito de EOP - em razão da ênfase na dimensão política em detrimento da análise da cultura e da dimensão simbólica consideramos que ele pode ser fértil para a análise dos movimentos docentes em meio às transformações ocorridas nas esferas do Estado. Mesmo tomando como base o conceito Gramsciano de Estado, que o concebe de modo integrado à sociedade civil, é certo que as fraturas no equilíbrio de poder ocupam lugar de relevo para a compreensão dos fatores que contribuíram para a emergência da mobilização coletiva dos professores.

As reconfigurações no sistema político apresentam-se como oportunidades para ensaiar mudanças, experimentar alianças, conquistar direitos. Deve-se levar em conta, contudo, os mecanismos identitários que desencadeiam esse processo, já que este depende da capacidade dos atores ou de suas lideranças identificarem os sinais, os acontecimentos que indicam uma possível oportunidade. Tal identificação pode derivar de uma declaração do Governo ou da manifestação de outros grupos que apontam para a existência das oportunidades políticas, promovendo-se um jogo de leituras e desencadeando uma bola de neve de movimentos e manifestações coletivas. Tanto no contexto português quanto no brasileiro, a própria iniciativa dos Governos Autoritários em promover uma abertura democrática controlada contribuiu para a intensificação dos movimentos de oposição ao regime e, também, para o acirramento da disputa em torno da reorganização política do país. 
Tomando como ponto de partida as quatro dimensões que fazem parte das EOPs citadas por Mc Adam - a saber 1) o grau de abertura (ou fechamento) relativos ao sistema político; 2) a estabilidade ou instabilidade do alinhamento das elites; 3) a presença e caracterização das elites alinhadas; 4) a capacidade e propensão do Estado para a repressão $\quad$ zaCesł 2003, p. 44) alerta que a utilização da noção de EOP deve ser cuidadosa e não se deve confiar na aparente transparência de seus mecanismos explicativos, cuja validade estaria circunscrita a formas estatais de desenvolvimento dos espaços públicos.

Além do mais, se deve notar que não existe uma relação unidimensional entre o grau de abertura do sistema político e os movimentos sociais, já que o sistema pode ser seletivo e combinar aberturas relativas a algum tipo de atores e obstáculos a outros. Desse modo, o autor assinala que as formas e conteúdos das lutas sociais e políticas atuam como motor da reestruturação do Estado e dos seus vários aparelhos, do mesmo modo que, como assinalava Marx, a forma e o conteúdo das lutas operárias condicionam a forma e o conteúdo das reestruturações produtivas. Assim, os movimentos difundemse, aproveitando as oportunidades políticas e, através de seus repertórios de ações, forçam o realinhamento dos diferentes atores da comunidade política, forjam e fazem com que se quebrem alianças e, nesse mesmo processo, podem forçar a aparição de novas oportunidades para si mesmos ou para outros movimentos sociais. (Cerezales, 2003, p. 43)

\section{A mobilização docente no espaço-tempo da transição democrática}

No contexto privilegiado pela pesquisa, o associativismo de caráter sindical entre os professores das escolas públicas do Brasil e de Portugal se institucionalizou nas décadas de 1970-80 como uma organização que teve como objetivo central confrontar o poder do Estado com vistas a reduzir os mecanismos de controle do Governo sobre o grupo profissional e, desse modo, aumentar a margem de autonomia política dos professores.

No Brasil, o movimento político-militar de março de 1964 inaugurou um período marcado pelo cerceamento da liberdade de associação e de manifestação pública, bem 
No âmbito do ensino, prevaleceram políticas de desresponsabilização do Estado frente à educação pública de qualidade, muitas vezes beneficiando a iniciativa privada por meio de subvenções e recursos públicos. Os Governos Militares realizaram Reformas, estabelecendo a profissionalização compulsória do ensino médio e unificando as formas de ingresso no ensino superior. A livre organização sindical dos funcionários públicos, em geral, e dos professores, em particular, foi proibida no período.

Acompanhando uma tendência internacional de falência dos regimes políticos autoritários nos países da Europa e da América, a sociedade brasileira viveu um período de transição política, que se estendeu de 1974 a 1985, tendo como marcos o anúncio da abertura democrática (lenta e gradual), conduzida pelos próprios Governos Militares com a Anistia, a reforma partidária e a eleição com voto vinculado e direto para a Assembleia Legislativa, Câmara dos Deputados, Senado e Governo do Estado, a partir do pleito de 1982. O ano de 1985 marca o momento em que a Presidência da República foi transferida a um civil, Tancredo Neves, selando o fim dos Governos Militares.

É relevante assinalar que a iniciativa do Governo se deu frente às pressões promovidas por forte mobilização popular, seja nas associações de moradores e nos grupos de pressão política, como o movimento pela Anistia, seja na organização de associações sindicais de categorias diversas como, por exemplo, a do magistério público. Essa ruptura no equilíbrio de poder foi acompanhada por uma série de ações e manifestações coletivas de professores com vistas a aprofundar as transformações políticas e superar as precárias condições salariais e de trabalho às quais o grupo profissional se encontrava submetido.

Em Portugal, o Estado Novo (1933-1974) promoveu o enquadramento ideológico do ensino e da juventude, da família, do trabalho e da cultura. Para Teodoro (2004) o regime salazarista exerceu um apertado controle da atividade docente nos campos ideológico e político, mas também no plano privado da moral e dos costumes. Nesse período, a proibição de todas as formas associativas e sindicais dos professores do ensino 

salarial dos professores comparativamente a outros funcionários da administração pública, indicam as linhas fortes da política educacional à época.

Contudo, ainda que o processo de abertura promovido por Marcelo Caetano (1968-1974) tenha buscado o afrouxamento das relações entre o Estado e a sociedade civil, a oposição política tendeu a se agravar ante as oscilações do Governo e aos crescentes descontentamentos com a crise econômica e as guerras coloniais. No âmbito da Educação, o período foi marcado pela gestão do Ministro Veiga Simão, interessado em estabelecer reformas tendentes à modernização do ensino, ainda que sob a vigência do regime autoritário.

Como se vê, em ambos os lados do Atlântico a derrocada dos regimes autoritários é antecedida pela tentativa dos representantes dos Governos de promover, sob seu próprio controle, o processo de abertura política. As formas de cada um dos Governos Nacionais sinalizarem esse empenho, assim como as respostas que caracterizaram a recepção coletiva - organizada ou em processo de mobilização - é que irão caracterizar os movimentos docentes, definindo o desenho das suas associações e os repertórios de ação coletiva por eles adotados.

Configuram, desse modo, contextos marcados pelo conflito entre concepções autoritárias e expectativas democratizantes, por movimentos organizados de contestação ao poder e tentativas governamentais de conduzir, sob seu próprio controle, as mudanças políticas requeridas naquela conjuntura.

De qualquer modo, em que pesem as expectativas partilhadas em nível global, os processos verificados em cada país configuram contextos muito específicos, com efeitos particulares sobre a organização da carreira docente e sobre a própria imagem dos professores públicos, seja no que tange à definição das funções sociais que eles são chamados a desempenhar, seja no que que se refere aos espaços de negociação política que eles passam a reivindicar junto às autoridades Governamentais. 
No Brasil, as greves e as grandes manifestações públicas de protesto e de denúncia das precárias condições salariais e de trabalho despontam como a parte mais visível do repertório de ações dos sindicatos docentes. Na medida em que obtinham resultados, as manifestações públicas, associadas ao estado de greve, alcançaram grande repercussão na imprensa diária e, por isso mesmo, geraram novas formas de ação com vistas a ampliar o capital simbólico adquirido pelos professores.

Em Portugal, a observação das ações coletivas desencadeadas pelos professores dos liceus demonstrou a centralidade de ações que se voltaram para a reestruturação das relações de poder no interior das escolas, promovendo-se o saneamento, isto é, a exoneração dos antigos detentores de cargos de direção, coordenação e similares e a introdução de processos eleitorais universais para a escolha dos novos quadros de direção das escolas, adotando-se, também, a forma de assembleias para instaurar o debate democrático e a participação de todos na definição de questões administrativas, didático-pedagógicas e políticas.

Conforme detalharemos adiante, as experiências de auto-gestão foram diferentes em cada escola, dependendo do equilíbrio instável entre forças de transformação e de conservação, assim como da multiplicidade de concepções a respeito do modelo ideal de sociedade e de escola defendido por diferentes indivíduos e grupos.

Nas próximas seções serão apresentadas algumas das ações promovidas pelos movimentos docentes brasileiro e português, a fim de observarmos as singularidades e, ao mesmo tempo, as questões representativas das respostas apresentadas pelos professores das escolas públicas em meio aos acontecimentos políticos que marcaram o período.

No Brasil, ocorreram greves e manifestações em vários estados. Para o interesse deste artigo, tomaremos as ações ocorridas no Rio de Janeiro como exemplares do repertório de lutas adotados pelos professores brasileiros.

\section{No Brasil: greves e manifestações de protesto}

O aprofundamento do processo de distensão democrática associado ao recrudescimento das demandas sociais e ao próprio fortalecimento da organização 
sindical dos professores interferiu na política educacional do estado do Rio de Janeiro. No âmbito da organização sindical docente, deu-se a criação da Sociedade Estadual dos Professores (SEP), em 1977, dois anos depois transformada em Centro Estadual dos Profissionais do Ensino (CEPE). E foi esta entidade sindical que liderou o movimento dos professores, recorrendo à greve. ${ }^{2}$

Assim, foram realizadas várias manifestações públicas, por meio das quais os professores saíram em passeatas, entoaram o hino nacional, acamparam em praça pública, enfim, ocuparam as ruas da cidade para chamar atenção sobre suas agruras profissionais e, também, para pressionar os parlamentares na condução das negociações pela melhoria do ensino público e do salário do magistério junto ao Governo. Com isso, eles foram granjeando apoio da sociedade e de algumas lideranças políticas, mas também tiveram que enfrentar situações de confronto aberto com as autoridades governamentais, encarando bloqueios policiais e, não raro, despertando os alarmes de pânico moral na imprensa (ADORNO, 1995 e LAWN, 2000) ${ }^{3}$.

A greve paralisou milhares de professores e empregados de apoio. O movimento incluiu negociações com as autoridades governamentais e com lideranças oposicionistas, além de manifestações públicas em frente à Assembléia Legislativa do Rio de Janeiro (Alerj). No contexto da abertura democrática, a greve deflagrada em 1979 teve repercussão nacional. Contudo, apesar daquele ser um contexto de ascensão dos movimentos sociais e das manifestações de oposição ao regime ditatorial, a imprensa jornalística manteve a sua postura reativa.

Com o recrudescimento dos movimentos grevistas de categorias diversas em vários estados do país, o Jornal do Brasil passou a tratar a greve dos professores do Rio de Janeiro como o indício de uma conspiração sindical nacional. Os títulos atribuídos aos editoriais que tratavam do assunto expressam claramente o posicionamento contrário à

\footnotetext{
${ }^{2}$ O Centro Estadual dos Profissionais de Ensino (CEPE) assumiu esta denominação a partir do Congresso Extraordinário de junho de 1988. Antes a entidade teve as seguintes denominações: Associação de Professores do Estado do Rio de Janeiro - APRJ (1977); Sociedade Estadual dos Professores - SEP (19771979) e Centro Estadual de Professores - CEP (1979-1988). Sobre o assunto ver: Sobreira (1989:74).

${ }^{3}$ Adorno e Lawn chamam atenção para o pânico moral que a sociedade aciona sempre que os professores rompem os pactos estabelecidos no que tange à neutralidade política e ao cumprimento das normas institucionalizadas e aceitas, ainda que com reservas, pelo conjunto da sociedade.
} 
do processo de radicalização política que, tomando a greve pela greve, ou seja, essencialmente como bandeira de oposição ao Governo (esta seria a intenção oculta), desconsiderava as dificuldades financeiras do estado e a disposição do governo em negociar uma solução para a crise (consubstanciando uma atitude inoportuna). Outro editorial, intitulado Em Tempo, cobrava do governo uma atitude mais ativa diante do movimento grevista, invocando o cumprimento da lei constitucional que proibia a greve de funcionários públicos à época.

Como de praxe, frente ao crescimento das manifestações de protesto, a imprensa manipulou os elementos que estariam na base da definição identitária dos professores. Conforme observamos, em situações nas quais os professores agem sem transgredir a linha de controle mantida pela autoridade governamental, os jornais mobilizam argumentos e princípios que valorizam e dignificam a sua conduta profissional. Já em situações de transgressão e de livre protesto, os jornais apresentam argumentos que cobram dos professores o exemplo moral e a fidelidade aos princípios de lealdade e neutralidade, correspondendo ao comportamento que deles esperam o Governo e a Sociedade, esta última representada de forma difusa e incerta na opinião pública veiculada pelos jornais. Por esse caminho, entramos na questão das relações de saber-poder, de manipulação das identidades em uma disputa em torno da força simbólica que estas exercem sobre a opinião pública e os próprios profissionais. Também se incluem nesse terreno a verificação dos sinais que identificam convergência ou afastamento dos professores e da própria imprensa em relação aos poderes estatais.

Com base nessas fontes, foi possível perceber, também, a maneira como a entidade sindical operou a construção de uma nova coesão identitária calcada na inclusão dos profissionais de apoio e na identificação entre todos os que trabalham na instituição escolar, independente da função que ocupam. Desse modo, eles acreditavam ser possível aproximar os professores à condição da classe operária, estendendo o seu potencial revolucionário para o grupo docente. Merece registro o adesivo muito utilizado nos 
pelas autoridades governamentais. Nas entrelinhas, mais uma vez, a identificação com a classe proletária, excluída e explorada, mas que, contando com a consciência política, seria capaz de se mobilizar para a luta e vencer as adversidades daquela conjuntura, modificando a história do país.

Em sintonia com o contexto da chamada normalização democrática, a greve de 1988 recebeu uma cobertura mais receptiva, tendo em vista, também, o seu caráter espetacular - pontuado por grandes manifestações públicas - e o apoio da Central Única dos Trabalhadores (CUT) e de lideranças dos partidos de oposição como o Partido Democrático Trabalhista (PDT) e o Partido dos Trabalhadores (PT). A greve por tempo indeterminado empunhou como reivindicação principal a reposição das perdas salariais da categoria, ${ }^{4}$ paralisou cerca de 140 mil professores e 60 mil empregados de apoio e teve três meses de duração - 13 de junho a 10 de setembro de 1988 (Alves,1984). Nesse período ocorreram cerca de dez manifestações públicas de protesto, contra as quais foram mobilizados policiais militares ostensivamente armados.

Merece registro uma manifestação que reuniu cerca de 4 mil profissionais da educação em frente ao Palácio Guanabara. O protesto foi rechaçado por forte aparato policial. Uma verdadeira praça de guerra foi montada pela Polícia Militar com cerca de 400 homens posicionados pelas imediações em pontos estratégicos, bloqueando todos os acessos que levavam ao Palácio. Impedidos de realizar a manifestação naquele local, os manifestantes procuraram demonstrar o caráter pacífico do movimento, objetivo que foi plenamente alcançado quando algumas professoras aproximaram-se do cordão de isolamento da Polícia Militar e atiraram flores brancas nos pés dos policiais, enquanto cantavam o Hino Nacional e a música de protesto de Geraldo Vandré - Pra não dizer que não falei de flores, como se vê na reportagem do Jornal O Dia, de 24/06/1988 (capa e p.3).

\footnotetext{
${ }^{4}$ As reivindicações salariais giravam em torno de $170 \%$ de reajuste e fixação de um indexador para os aumentos salariais fornecido pelo Departamento Intersindical de Estudos Econômicos, Sociais e Estatísticos (DIEESE) com base no Índice de Preços ao Consumidor (IPC).
} 
Esses acontecimentos deixam claro que a organização coletiva dos professores, por meio de seus sindicatos, também se utilizou da imprensa para ampliar a repercussão pública de suas ações e, ao mesmo tempo, para intensificar a pressão para o atendimento de suas reivindicações. O melhor exemplo do uso racional da imprensa pelo Sindicato foi o caráter espetacular que a greve de 1988 apresentou. Explorando simbologias arquetípicas - como as que se encontram contidas nas relações de força / brutalidade (policiais fortemente armados com escudos e cassetetes) e inteligência / delicadeza (professoras depositando flores nos pés dos policiais); o sentimento nacionalista despertado pela entoação coletiva do hino nacional e outros aparatos simbólicos (tais como o adesivo largamente utilizado nos carros) - o movimento docente se fez noticiar, mobilizando o debate em torno de suas reivindicações em contraste com o tratamento dispensado pelo Governo.

Enfrentando reações contrárias - as previstas e as imprevistas - as manifestações públicas dos professores contribuiriam para que os sindicatos desempenhassem, cada vez com maior eficácia, ações que visavam granjear o apoio da população e, ao mesmo tempo, divulgar a falta de compromisso do Governo com a educação pública. As manifestações públicas, aqui descritas, evidenciaram os limites e os avanços alcançados por meio das ações coletivas dos professores. Por meio delas, os professores criaram um espaço próprio - a que vamos chamar de zona de negociação - por meio do qual eles confrontaram e, ao mesmo tempo, se fizeram representar junto ao Estado, exercendo pressão e envolvendo a sociedade civil de modo amplo, tendo em vista a repercussão na imprensa.

Provavelmente por terem ocorrido no período de reestruturação da vida democrática - marcado pela convocação da Assembleia Constituinte e pelo retorno das lideranças de esquerda que estiveram no exílio e que, a partir de então, passaram a ocupar cargos eletivos - as manifestações dos professores receberam uma cobertura mais ampla dos jornais de grande circulação no Rio de Janeiro. Contudo, como vimos por meio deste e dos demais exemplos citados, nem sempre os resultados alcançados na abertura dessas zonas de negociação podem ser previstos e controlados, no sentido de se definir, previamente um resultado positivo. 
De qualquer forma, estes configuram acontecimentos a partir dos quais foi possível observar a força, os contornos e as contradições dos espaços de autonomia abertos pelas manifestações públicas e pelos movimentos dos professores. Acreditamos que a observação desses movimentos na longa duração, ou seja, em perspectiva histórica, poderá fornecer elementos que nos ajudem a perceber a estreita relação entre a dinâmica dos movimentos sociais e das ações coletivas docentes em sintonia com os contextos históricos e as conjunturas políticas que emolduram a vida social, as práticas culturais e a experiência individual e coletiva.

Nos casos analisados, foi possível perceber, também, em que medida o sindicato modificou o seu repertório de ações em consonância com o aprendizado adquirido com a experiência, logrando planejar novas ações a partir das reações contrárias previsíveis de modo a obter resultados favoráveis aos seus objetivos. Assim, torna-se evidente que as ações coletivas e as associações docentes se constituem não apenas como resultado das imposições do Estado, mas também com base no aprendizado adquirido em ações anteriores, funcionando como fatores, tal como ocorreu no contexto dos anos 1970 nos dois países (e em outros países da América Latina e da Europa) no curso das mudanças sociais.

Acreditamos que as manifestações públicas amplamente noticiadas nos jornais sintetizam momentos em que os professores se organizam e ganham visibilidade como grupo profissional, afirmando suas concepções, reivindicando direitos e denunciando a atuação do poder público em relação às condições de trabalho e de efetivação de uma atuação profissional condizente com a construção da vida democrática que o país requeria. Nesse sentido, reivindicavam do Estado as condições necessárias para atender às aspirações da sociedade ao mesmo tempo em que afirmavam, em alto e bom som, que era necessário, antes de tudo, atender às necessidades salariais e garantir condições laborais exequíveis para o bom desempenho do grupo profissional.

\section{Em Portugal: mobilização docente e autogestão da escola}

Em Portugal, o Estado Novo (1933-1974) articulou uma política educacional na qual o aparelho escolar, em particular a escola primária, se encontrava submetido a uma 
política de contenção, seja em sua expansão quantitativa, seja no que tange ao exercício da autonomia intelectual, cívica e moral dos alunos, seja na seleção e manutenção do quadro de professores. A esta orientação, o Governo combinou uma política cultural extremamente abrangente, fincada na propaganda dos ideais propalados pelo regime e na censura a tudo o que destes se afastasse (MOGARRO, 200, p. 88.) .

Já no período da abertura Marcelista, ocorreu a realização do Congresso de Aveiro, ${ }^{5}$ em 1971, em pleno período de discussão pública acerca da Reforma educacional proposta pelo Ministro Veiga Simão. Realizado em um contexto no qual a falta de liberdades políticas, de reunião, de associação e de expressão predominava sobre a vida social e escolar, o Congresso funcionou como válvula de escape das expectativas de mudança política, até então, contidas pelo regime político opressor.

Nesse processo, a mobilização dos docentes do ensino liceal teve nos Grupos de Estudo do Pessoal Docente do Ensino Secundário (GPDES) ${ }^{6}$ um espaço que propiciou a sua organização coletiva. A realização dos Congressos do Ensino Liceal canalizou, ainda, as manifestações de desaprovação da Reforma, ${ }^{7}$ se estendendo pelo processo de transição marcado pela sucessão de Governos Provisórios até a promulgação da

\footnotetext{
${ }^{5}$ Em resultado de uma troca de impressões ocorrida em uma sessão de trabalho aberta a todos os professores, havida em julho de 1970, no Liceu Nacional de Aveiro, o ministro Veiga Simão teria proposto a organização de um novo congresso de professores do ensino secundário. (Grácio,1983:760).

${ }^{6}$ Os Grupos de Estudos do Pessoal Docente do Ensino Secundário e Preparatório (GEPDES) representam a forma adotada por professores de vários pontos do país que se movimentaram no ano de 1970/71, lutando pela estabilidade de emprego ( $84,2 \%$ dos docentes em exercício no país eram provisórios ou eventuais e não tinham garantia de emprego e apenas ganhavam durante nove ou dez meses por ano), por um Estatuto dignificado, por uma Associação de Professores. A primeira reunião nacional dos GEPDES teve lugar em Coimbra em 6 de Março de 1971, e a ela se seguiram outras 39 realizadas em diversas cidades até 28 de Abril de 1974. Cf: www.apagina.pt aceso em 11/10/2007, às 17:45 h.
}

7 Como parte do Programa do I Governo Provisório, o desenvolvimento da Reforma Educativa conduzida pelo Ministro da Educação Veiga Simão pode ser resumida com base nas orientações genéricas presentes no referido Programa de Governo, inscritas no item 8 - Política educativa, cultural e de investigação, que teve como principais eixos: a) Mobilização de esforços para a erradicação do analfabetismo e promoção da cultura, nomeadamente nos meios rurais; b) Desenvolvimento da reforma Educativa, tendo em conta o papel da educação na criação de uma consciência nacional genuinamente democrática e a necessidade da inserção da ecola na problemática da sociedade portuguesa; c) criação de um sistema nacional de educação permanente;

d) Revisão do estatuto profissional dos professores de todos os graus de ensino e reforço dos meios ao serviço da sua melhor formação; e) (...) Implantação do princípio da igualdade de oportunidades f) Criação de esquemas de participação de docentes, estudantes, famílias e outros interessados na reforma educativa, visando, em especial, a liberdade de expressão e a eficiência do trabalho. [Decretolei 203/74, de 15 de maio]. Cf: Teodoro, 2004:183-184. 
Constituição Republicana em 2 de abril de 1976. A esta associação docente, se somou a circulação da Revista O Professor, ${ }^{8}$ configurando ações a partir das quais os docentes potencializaram as oportunidades abertas pela mudança política em curso.

A esse respeito, merece destaque a observação de João Barroso, para quem o ciclo de evolução do sistema de ensino português, que se inicia no "25 de abril de 1974" e se extingue progressivamente com a posse do primeiro governo constitucional, em 1976, pode ser caracterizado como "um período de forte participação social, por vezes espontânea e radical, mas quase sempre radicalizada pelas vanguardas partidárias, empenhadas em eliminar (ou esconder) os vestígios do passado antidemocrático e em disputar a primazia na definição do futuro" (Barroso, 2003, p. 66).

Também é digna de nota a observação de Antônio Teodoro (2004), assinalando que, no processo de redemocratização da sociedade portuguesa, o controle do Estado perde sua força ante as escolas, onde as nascentes estruturas sindicais dos professores começavam já a assumir um papel de destaque no campo escolar, ora se antecipando, ora se recusando a aceitar quaisquer normatizações oriundas do Estado, contrariando, dessa forma, as expectativas de promover uma "transição controlada", por parte dos Governos Provisórios que se sucederam até 1976. Interessa destacar com Teodoro (2004, p. 184) que, nos trabalhos sobre a revolução portuguesa de abril, existe um assinalável consenso sobre duas de suas características marcantes: 1) a existência de forte movimento social popular, que impulsionou as principais transformações verificadas na sociedade portuguesa e 2) a paralisia generalizada no seio das estruturas do aparelho de Estado, em resultado da luta pelo seu controle político.

Por sua vez, João Barroso propõe uma cronologia histórica do processo de construção do sistema educativo português após a instauração do regime democrático (1974-2002), descrita a partir de definição de quatro grandes ciclos temporais, organizados de acordo com a dinâmica social dos processos de mudança e do leitmotif

\footnotetext{
${ }^{8}$ O Professor surge, sob a forma de Caderno, em um tempo marcado por expectativas e projetos de mudanças, abarcando tanto o contexto da "abertura marcelista" e da Reforma Veiga Simão quanto o território da iniciativas autônomas destinadas a reativar o associativismo docente. É digno de nota o fato de a maioria dos professores responsáveis pela revista estar ligados ao movimento associativo, inicialmente os Grupos de Estudo, posteriormente ao sindicalismo docente. Dentre os docentes que exerceram cargos editoriais na Revista encontram-se António Teodoro e Maria Júlia Jaleco, Costa Carvalho e Reis Monteiro, Maria do Céu Araújo e Rogério Fernandes. (Cf: Nóvoa,1993, p. 726-727).
} 
diversificado e descentrado que punha em causa a lógica reformista do Estado, antecipando-se aos seus desígnios e consumando as mudanças independentemente de qualquer alteração dos normativos." (BARROSO, 2003 p. 66).

São esses, aspectos extremamente relevantes para compreendermos as formas de relacionamento criadas em meio ao deslocamento das estruturas de poder e de transição política, processos nos quais se deu a ruptura do controle do Estado sobre a dinâmica das instituições escolares, particularmente no que se refere à sua configuração como espaço de socialização profissional, deixando, ao menos em tese, um campo aberto para a participação autônoma dos professores em seu ambiente de trabalho. Acompanhar a movimentação dos docentes do ensino liceal em meio a esse complexo processo histórico - caracterizado (dentre outros fatores) pela combinação entre mobilização política e social e desorganização do controle estatal - nos ajudou a entender porque o processo revolucionário que culminou com o 25 de abril de 1974 desencadeou uma sucessão de experiências de autogestão nas escolas públicas, introduzindo experiências que influenciaram a organização escolar e a legislação educacional no período posterior.

Em artigo publicado na Revista O Professor, uma das lideranças sindicais da época (BENTO,1976) alertou para o fato de que o resultado das eleições para as associações de alunos, em muitos liceus e até em escolas técnicas, acabou garantindo nítida vitória para as forças reacionárias. Refletindo sobre a dinâmica mais geral da sociedade portuguesa da época, Bento considerou que as estruturas que enquadravam os jovens dentro e fora da escola foram mais fortes que as suas possibilidades de contestação vigentes no seu modo de funcionamento.

Em análise retrospectiva desse movimento, Maria de Fátima Chorão Sanches (2004) nos oferece uma instigante análise das narrativas dos professores em relação à gestão das escolas no contexto de abertura proporcionado pelo movimento de 25 de abril até o chamado período de normalização. A autora identifica os tipos de liderança 

interferir no funcionamento da escola com vistas à conquista da autonomia. Com base em entrevistas realizadas com professores que tiveram liderança na gestão de escolas, à época, a autora destaca o ativismo transformador dos professores entrevistados no que tange à construção da escola democrática, introduzindo novos mecanismos de interação e decisão entre os atores intervenientes no funcionamento interno das instituições escolares.

Os depoimentos concedidos pelos professores entrevistados por Sanches (2004, p.142-3) destacaram o valor atribuído ao rompimento com formas de agir tradicionais e sublinharam a colaboração com grupos politicamente ativos, referindo-se à ilusão partilhada por muitos de que o clima revolucionário permitiria transformar a subversão e a repressão em liberdade de agir, de ensinar e de partilhar novas ideias. Acreditavam no potencial socializador da escola e em uma prática pedagógica interdisciplinar, ancorada na análise crítica de eventos sociais e políticos, eliminando a hierarquia entre os saberes escolares e os da experiência, derrubando tabus e valorizando a reflexão sobre o presente.

De acordo com esta autora, (SANCHES, 2004, p.149) uma das ideias fortes das ações exercidas nos estabelecimentos escolares era a do poder da escola, fundada na crença de que mudar a escola poderia conduzir à mudança social. Nesse contexto, algumas escolas lograram associar à inquietação que a todos atingia a adoção de uma política institucional voltada para a construção da autonomia. E, de fato, em algumas escolas, tornou-se possível eliminar o autoritarismo e ampliar os mecanismos de participação sem perder eficácia no seu modo de funcionamento, promovendo-se um alargamento de suas fronteiras e articulando à sua dinâmica de funcionamento o debate das grandes questões da política educacional da época, tais como a formação de professores, seu estatuto profissional e a própria organização escolar.

Todavia, a autora (SANCHES, 2004, p.144-147) alerta que as mudanças não se fizeram em todas as escolas simultaneamente nem derivaram de posições idênticas. Por 
exemplo, dentro de uma mesma escola, conviviam posições de ativismo e de resistência e rejeição à mudança, tendentes à acomodação. Em geral, nos grandes liceus, teve maior peso o tradicionalismo representado pelas professoras mais antigas na escola. Quando muito, nas escolas que prezavam o estatuto adquirido no regime anterior, criou-se um equilíbrio democrático assente mais na ideia de representatividade do que em hábitos organizacionais de participação e decisão capazes de criar uma política de autonomia para a escola. O clima de mudança diferenciou-se de escola para escola, sendo por conflito em umas e, em outras, por meio de uma passagem suave de poder, do reitor para os representantes da escola - professores, alunos e funcionários - ou, transitoriamente, para o professor mais antigo da escola. Criaram-se os primeiros grupos de trabalho que se transformariam nas Comissões de Gestão.

Avalia, ainda, que os conflitos se remetiam mais às divergências partidárias e de implementação de medidas do que propriamente em relação aos princípios adotados, recrudescendo quando se tratou de contestar as ingerências do Ministério da Educação nos hábitos de soberania revolucionária instalados em algumas escolas. De modo inverso, em outras escolas, a democratização da gestão interna foi adotada por obediência ao primeiro decreto-lei (n. 221/74), por meio do qual o Ministério da Educação oficializou as mudanças já em curso em muitas escolas.

Contudo, deve-se fazer a ressalva de que no período posterior ao 25 de abril, estas conquistas teriam oscilado entre o aprofundamento das práticas e dispositivos tendentes à democratização e as sucessivas reformas tendentes à burocratização e à contenção da gestão democrática. Como avaliou Licínio Lima (2001), o decreto 769-A/1976 de 23 de outubro que regulamentou as estruturas de gestão das escolas de ensino preparatório e secundário (hoje segundo e terceiro ciclos do ensino básico e ensino secundário) reconfigurou os processos autogestionários em curso à época, estabelecendo normas nesse sentido, mas, também, burocratizando a participação espontânea dos professores em longas e concorridas assembleias, na medida em que imputou este poder ao Conselho Diretivo e ao Conselho Pedagógico, criados pelo referido decreto. 


\section{Considerações Finais}

O que moveu a pesquisa que ancora os resultados aqui apresentados foi a perspectiva de traçar uma história da profissão docente centrada no protagonismo destes atores, observando as estratégias mobilizadas individual e coletivamente no sentido de reestruturar espaços próprios de interação institucional e socioprofissional para, desse modo, reconstruir as bases definidoras de sua identidade profissional. ${ }^{9} \mathrm{~A}$ capacidade de exercer pressão política, bem como as demonstrações de competência profissional são estratégias exemplares das possibilidades de reconversão da posição ocupada pela categoria docente nos jogos de poder.

Nos processos analisados, a noção de construção democrática se apresentou como conceito unificador por meio do qual os princípios teóricos e as estratégias de lutas dos diferentes grupos - para além de suas filiações partidárias e de seus respectivos projetos de sociedade - foram articulados. Nesse sentido é que se explica a importância atribuída à gestão democrática no movimento docente português. Aliás, essa questão coloca em relevo, também, a percepção de que a política não se restringe ao poder formal e não é atribuição exclusiva do aparelho de Estado, mas emerge do próprio movimento social, envolvendo a sociedade civil, seja como componente do Estado, seja sob a forma de organizações coletivas, ora negociando, ora se antecipando às regulações estatais.

No que se refere aos espaços próprios da luta de reconstrução democrática, a escola aparece em primeiro plano, na prática e na produção intelectual articulada aos movimentos docentes portugueses. A esse respeito, a expressão "construção da escola democrática" faz parte da narrativa dos sujeitos entrevistados, assim como das publicações atinentes a esses movimentos. Na prática, as tensões e contradições observadas no percurso de autogestão das escolas secundárias portuguesas a diversidade de condições na qual esse processo decorreu em cada escola, revelaram os limites da crença em uma democracia direta, na qual todos discutem em

\footnotetext{
${ }^{9}$ Partindo do princípio de que as identidades (profissionais) são o resultado, a um só tempo, estável e provisório; individual e coletivo; subjetivo e objetivo; biográfico e estrutural dos diversos processos de socialização que, conjuntamente, constroem os indivíduos e definem as suas instituições, Claude Dubar (2005, p. 136) sugere que o sindicalismo pode construir, por exemplo, um aparelho de socialização secundária que permita a transformação das identidades dominadas em identidades militantes, resistindo à dominação e contribuindo para a produção de novas regras em jogo (Dubar,2005, p.128).
} 
igualdade de posições, sem hierarquias marcadas e, aparentemente, sem constrangimentos ou restrições externas. A lição que se pode ler na experiência portuguesa é que o processo democrático implica a permanente tensão entre as forças autoritárias, que permanecem, com maior ou menor espaço de intervenção, e as forças democráticas que, a partir de então, lutam para se tornaram dominantes e ganharem estabilidade (AVRITZER, 1995).

Quando observamos os participantes, as entidades e instituições envolvidas nos processos de luta, com seus repertórios de ação e em suas repercussões, torna-se possível perceber uma multiplicidade de interferências na definição dos pontos centrais das agendas desses movimentos. Nas manifestações públicas de professores do Rio de Janeiro, despontam os jogos de efeito simbólico para chamar a atenção da opinião pública. Mas é certo que as repercussões nem sempre foram previsíveis e controladas, seja pelos movimentos, seja pelo próprio Estado.

As análises das matérias relativas à greve dos professores evidenciaram, ainda, as estratégias de manipulação pelo discurso jornalístico de elementos identitários, tais como: a influência desagregadora de elementos individuais filiados a partidos e projetos políticos divergentes daqueles que alcançaram hegemonia na ordem social vigente; as ênfases no profissionalismo da categoria em oposição ao politicismo que imperaria em épocas de greve; a ideia predominante nos jornais segundo as quais os professores são encarados como modelos de conduta em relação a seus alunos e a sociedade, ao lado da condenação pela quebra do contrato segundo o qual professores deveriam se portar como exemplo moral da mocidade, assumindo como norma de conduta uma postura de neutralidade - política, intelectual, pessoal =se aciontacaradoreivindicações econômicas, bem como das disputas políticas do momento. Desse modo, buscaram impor uma moldura identitária aos professores, por assim dizer, com traços sobrehumanos, alheia às necessidades e vontades desse mundo, acomodada e submissa ao status quo dominante.

Por outro lado, também os professores, por meio de suas associações e, sobretudo, utilizando-se da imprensa pedagógica, promoveram a difusão de marcadores identitários pertinentes aos seus projetos políticos e profissionais. A esse respeito, é 
pertinente destacar as observações de Pintassilgo (2008). Ao analisar a imprensa pedagógica, em particular aquela ligada ao associativismo docente no período republicano, o autor observa que a criação de associações de professores e de sua imprensa propiciaram o desenvolvimento de um contexto intelectual e afetivo favorável à socialização docente, lançando crenças e valores próprios à profissão, contribuindo, desse modo, para a difusão de representações sobre a profissão e a fixação do sentimento de pertencimento a uma mesma comunidade simbólica (PINTASSILGO, 2008, p. 80). Assim, torna-se visível o campo de disputas que se configura em torno da construção das identidades docentes, tendo como palco as manifestações públicas, os jornais de grande circulação e os impressos ligados a associações de caráter sindical e profissional.

Cabe finalizar, com base nas ponderações de Leonardo Avritzer (2000), que a confrontação entre as experiências de associativismo docente aqui analisadas e o descrédito - cada vez mais partilhado nos dias atuais - acerca das virtualidades democráticas da escolas, assim como nas possibilidades de ampliação dos espaços de autonomia dos professores, demonstraram que a noção de transição democrática deve partir da problematização do próprio conceito de transição e de redemocratização, propondo que se ampliem os marcos nos quais a democracia é pensada para além dos processos de continuidade e ruptura, de modo a perceber a transição de um sistema democrático-elitista instável para um sistema democrático mais institucionalizado e participativo a partir das dinâmicas movidas pela luta entre grupos e forças políticas concorrentes, no qual a sociedade civil e os atores políticos democráticos desempenham papel de permanente luta, alternando de modo recorrente as correlações desiguais de forças e de ideologias políticas.

\section{Referências}

ADORNO, Teodor. Educação e emancipação. Tradução de Wolfgang Leo Maar. Rio de Janeiro: Paz e Terra, 1995.

ALVES, M. H. M. Estado e oposição no Brasil (1964-1984). Petrópolis, Vozes, 1984. 
AVRITZER, Leonardo. Cultura política, atores sociais e democratização: uma crítica às teorias da transição para a democracia. RBCS, n.28, ano 10, jun. 1995.

BARROSO, João. Organização e regulação do ensino básico e secundário, em Portugal: sentidos de uma evolução. In: Educação e Sociedade. Campinas, vol.24, n. 82, p.63-92, abril.

BARROSO, J. A regulação das políticas públicas de educação: espaços, dinâmicas e atores. Lisboa: Educa, 2006.

BENTO, José Gomes. Gestão democrática nas escolas secundárias. O Professor. $\mathrm{n}^{\circ} 13$, abril, p.8-9.1976

CEREZALES, Daniel Pereira. O poder caiu na rua: crise de Estado e ações coletivas na Revolução Portuguesa (1974-1975). ICS-Universidade de Lisboa, 2003

DUBAR, Claude . A Socialização: construção das identidades sociais e profissionais. São Paulo, Martins Fontes, 2005

CUNHA, Luís Antonino . Educação e desenvolvimento social no Brasil. Rio de Janeiro: Editora Francisco Alves, $5^{a}$ edição, 1980.

GOHN, Maria da Glória. Teorias dos movimentos sociais: paradigmas clássicos e contemporâneos. São Paulo: Edições Loyola, 2008.

GRACIO, Rui . O congresso do ensino liceal e os grupos de estudo do pessoal docente do ensino secundário. Análise Social, v.. XIX , n.77-78-79, -p. 757-79, 1983

LAWN, Martin. Os professores e a fabricação de identidades. In: A. NÓVOA, Antonio \& JURGEN Schriewer (Eds.). A difusão mundial da escola. Lisboa: Educa, 2000, p. 69-84

LIMA, Licínio . Vinte e cinco anos de gestão democrática em Portugal. 2001. (Mimeo)

MCADAM, TARROW E TILLY Para mapear o confronto político. In: Lua Nova, São Paulo, vol.76, p. 11-46, 2009.

MCADAM, Doug. Conceptual origins, current problems, future directions. In:

MCADAM; MCCARTY e ZALD, M. (Eds). Comparative perspectives in social movement research. Cambridge: Cambridge University Press, 1997, p.23-40.

MOGARRO, M. J. A Formação de professores primários no Portugal Contemporâneo: a Escola do Magistério Primário de Portalegre. Tese (doutorado) - Universidade de Lisboa, Doutorado em Ciências da Educação, 2001. 
NÓVOA, António. A imprensa de educação e ensino: repertório analítico (séculos XIX e XX). Lisboa: Instituto de Inovação Educacional. 1993. Coleção Memórias da Educação (p.726-727).

PINTASSILGO, Joaquim. O associativismo docente do ensino liceal português durante o período republicano e a sua imprensa: As representações dos professores sobre a profissão e a construção de identidades. Revista Lusófona de Educação, vol12 , Lisboa, p.79-96, 2008.

SANCHES, Maria de Fátima Chorão. A construção discursiva da liderança escolar dos professores: da práxis revolucionária ao tempo de normalização. Revista Portuguesa de Educação, Universidade do Minho, n. 17 (2), p. 132-178, 2004.

TEODORO, António. Mobilização educativa em tempos de crise revolucionária: periferia e centro no processo de democratização das escolas (1974-1976). Revista Portuguesa de Educação. Univ. do Minho. Ano 17 n. 2004. Disponível em: http://www.redalyc.org/articulo.oa?id=37417207 >. Acesso: 002. 05/11/2020, às 15 h.

Recebido em: 16/07/2013 Aprovado em: 04/11/2013

Universidade do Estado de Santa Catarina - UDESC

Programa de Pós-Graduação em História - PPGH

Revista Tempo e Argumento Volume 05 - Número 10 - Ano 2013 tempoeargumento@gmail.com 